\title{
16 THE ROLE OF INFORMATION TECHNOLOGY IN THE LEARNING OF KNOWLEDGE WORK
}

\author{
Valerie Spitler \\ New York University \\ U.S.A. \\ Michael Gallivan \\ Georgia State University \\ U.S.A.
}

\begin{abstract}
Knowledge work is increasingly important in post-capitalist society (Drucker 1993, 1995) and is associated with new organizational forms and ways of working (Lucas 1996). These include flatter, less hierarchical organizational structures; more fluid job definitions and reporting structures; more competitive and faster paced work environments; and an increased reliance on information technology. (IT) to perform work (Ruhleder, Jordan and Elmes 1996). Initiating knowledge workers into such firms and working environments and ensuring their continued performance and productivity will be critical to firms and may require new management practices. The purpose of the present research is to develop a theoretical framework which explores and describes how knowledge workers learn their jobs and the role that using IT plays in this process. Founded on the assumptions that learning and problem-solving are critical to knowledge work, and are socially constructed, situated in practice, and contextspecific, the research presented here is part of an on-going interpretive case study based on theoretical underpinnings derived from the theory of legitimate peripheral participation (Lave and Wenger 1991). To develop this framework, one of the authors has gained access to a global strategic management consulting firm with offices in New York
\end{abstract}


City where she is using ethnographic methods of interviewing and participant observation. This paper presents early results of the study, focusing specifically on how entry-level consultants, analysts and associates, learn and perform their jobs, and the role that using IT plays therein. The research is expected to have implications for training, mentoring and incentive policies for organizations operating in the IT-based, knowledge economy.

Keywords: Knowledge work, information technology, situated learning, interpretive case study, IS usage, community of practice.

"And even if outnumbered by other groups, knowledge workers will be the group that gives the emerging knowledge society its character, its leadership, its social profile."

Drucker 1995, p.233

"The knowledge [worker] may need a machine, whether it be a computer, an ultrasound analyzer, or a radio telescope. But neither the computer nor the ultrasound analyzer nor the telescope tells the knowledge [worker] what to do, let alone how to do it. Without this knowledge, which is the property of the employee, the machine is unproductive."

Drucker 1993, pp. 64-65

\section{Introduction}

Knowledge work is increasingly important in the post-capitalist (Drucker 1993, 1995), post-industrial (Bell 1973), information age society. Not only do knowledge workers make up an increasing percentage of our labor force, but they also embrace an important leadership role in society (Drucker 1995). Organizations are striving to understand and manage knowledge work (Davenport, Jarvenpaa and Beers 1996; Zand 1997) and the role that information technology (IT) plays in performing it (Fisher and Fisher 1998; Mankin, Cohen and Bikson 1996; Orlikowski 1996). Their attempts have illuminated the complexity of knowledge work and workers' interaction with technology (Orlikowski 1992), and have highlighted the social-cognitive nature of the work (Barley 1990; Tyre and Orlikowski 1994).

Knowledge work is associated with new organizational forms and ways of working (Lucas 1996). These include flatter, less hierarchical organizational structures; more fluid job definitions and reporting structures; more competitive and faster paced work environments; and an increased reliance on IT to perform work (Ruhleder, Jordan and Elmes 1996). Initiating knowledge workers into such firms and working environments and ensuring their continued performance and productivity will be critical to firms and may require new management practices.

The purpose of the present research is to develop a theoretical framework which explores and describes how knowledge workers learn their jobs and the role that using 
IT plays in this process. Founded on the assumptions that learning and problem-solving are critical to knowledge work, and are socially constructed, situated in practice, and context-specific, the research presented here is part of an on-going interpretive case study based on theoretical underpinnings derived from the theory of legitimate peripheral participation (Lave and Wenger 1991). To develop this framework, one of the authors has gained access to a global strategic management consulting firm with offices in New York City where she is using ethnographic methods of interviewing and participant observation.

This paper presents early results of the study, focusing specifically on how entrylevel consultants, analysts and associates, learn and perform their jobs, and the role that using IT plays therein.

The research is expected to have implications for training, mentoring and incentive policies for organizations operating in the IT-based, knowledge economy.

\section{Assumptions Underlying the Research}

The present research deviates from the dominant view of IT use as occurring with a single system or set of functions, by a single, isolated individual, and to a greater or lesser degree. Such a view is appropriate for studying the interaction of a single individual with a single system such as in cognitive science or human factor studies (Kling and Scacchi 1982), but is inappropriate for understanding how workers interact with IT in an organizational setting. Thus a social-cognitive perspective is proposed here in order to understand the relation between knowledge workers and IT. This perspective relies on the notion of communities of practice (Brown and Duguid 1991; Lave and Wenger 1991), which "imply participation in an activity system about which participants share understandings concerning what they are doing and what that means in their lives and for their communities" (Lave and Wenger 1991, p. 98). Knowledge workers do not use IT in an isolated manner, but rather operate within communities of practice, whether it be lawyers using a document management system within the law practice to prepare a client case, stock brokers and sales assistants using multiple database and analysis systems within an investment management firm to make investment recommendations, or management consultants using a variety of desktop information technologies working in teams to understand and solve client problems.

This research proposes that, at the same time that IT use occurs within a community of practice, it is also more complex than typically viewed in the IS literature. IT use among knowledge workers need not always be limited to a single system or set of functions, even when knowledge workers are solving a single problem. Further, given their higher levels of education and training (Drucker 1995) and the unstructured and creative nature of knowledge work, knowledge workers are more likely to manipulate information technology to meet the demands of their work. Manipulation may include not only changing options and parameters of systems (Devin 1994), but also (1) modeling relations in the data, (2) combining information and functionality from multiple sources, (3) revising parameters based on reasonableness of data, etc. Thus, use of IT is expanded to include not only a relatively passive activity of using an information system where data, features and functionality are relatively fixed and well designed to support 


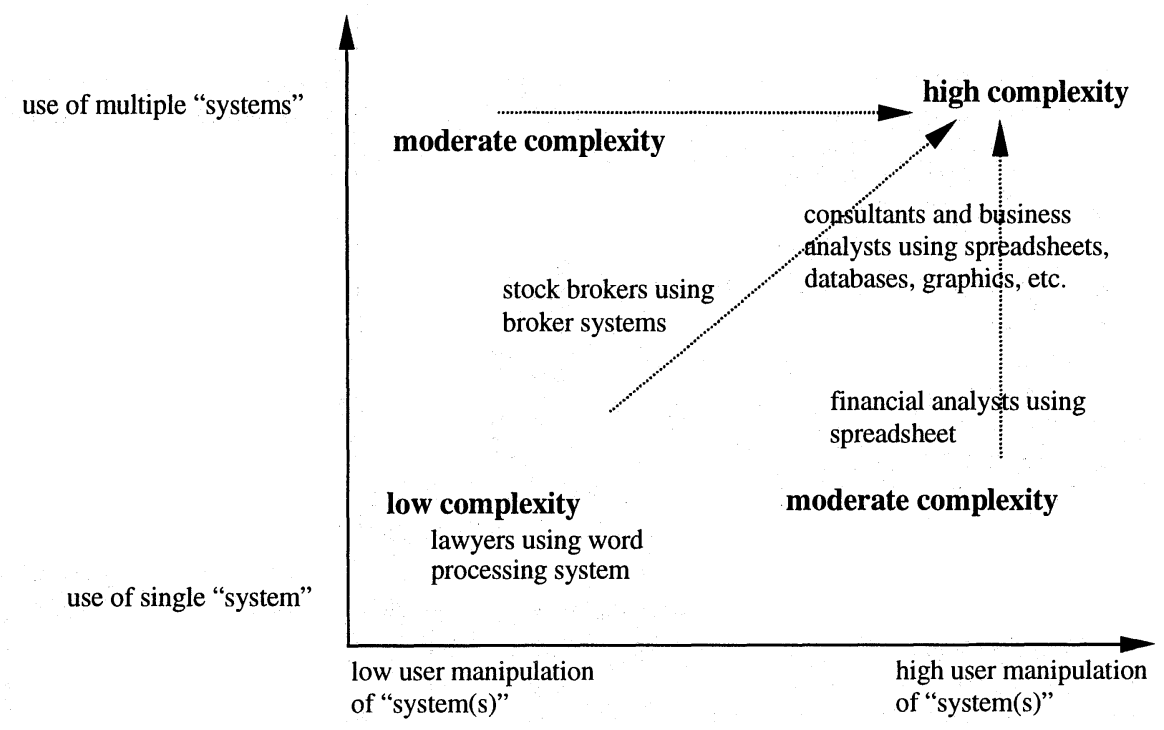

\section{Figure 1. Examples of Knowledge Workers and Their Use of IT (working within community of practice)}

specific structured work (Turner 1984), but also as an engaging activity where the workers, in the extreme, may determine which particular technology to use, which data to include, which features and functions to use and what parameters and options to change. The view of IT use proposed in this research is depicted in Figure 1.

The bottom axis represents the degree of manipulation users make to their information technologies, while the left axis represents the number of systems or functionalities they use. Much of early IS research investigated workers using a transaction processing system; workers using such a system are limited to using a single system and make minimal manipulations to the system. This type of use falls in the lower left quadrant of the diagram and seems to represent the assumption underlying much of current IS research. Knowledge workers' use of IT today is generally more complex than that of these early users. The trend is for their use of IT to become more complex, for them to use multiple information technologies and to perform a high degree of manipulation. This highly complex use is represented in the upper right quadrant of the diagram and represents the type of knowledge workers who are the subject of the present research.

This research proposes that our understanding of how IT is used to support knowledge work can be enhanced if we adopt a characterization of IT use as

- having a high intellectual (cognitive) component,

- occurring within a community of practice,

- being both a medium and an outcome of human action, enabling and constraining it,

- varying in its complexity in terms of the number of "systems" (i.e., functionalities) used and the degree of manipulation of those "systems." 
While the first three characterizations have been discussed explicitly in the literature, the last is an assumption unique to the present research.

Viewing the use of IT as a social-cognitive activity underlies and guides the present research. This perspective should provide valuable insights over and above those achieved by many prior studies. It allows examination of workers actively engaged in using IT in their natural environments. The intention of the research is to reveal and explore fundamentally how knowledge workers use IT for performing their work, while avoiding the adoption of simplistic and limiting assumptions.

\section{Information Technology Use in the IS Literature}

There is a growing concern within organizational, operations management and IS literature about the role that IT plays in performing knowledge work (Davenport, Jarvenpaa and Beers 1996; Drucker 1995; Laudon and Starbuck 1994). This type of work and the role that IT plays in performing it, however, has not been adequately explored. The results which can be gleaned come from two types of IS research. The first are positivist studies which attempt to predict workers' use of IT (see, for example, De Lone and McLean 1992), usually as part of the implementation research. The second type of IS research views workers' use of IT as integrated into their jobs, often by the workers themselves. This integrated perspective is represented in the work of researchers such as DeLong (1997), Orlikowski $(1992,1996)$, and Schultze (1999) takes an interpretive perspective, and is often concerned with organizational changes associated with using IT. Given the relatively recent expansion of knowledge work in our economy, as well as the variety of IT to support it, and the few interpretive studies on knowledge workers, it is not surprising that few research models or results are forthcoming.

One theory in particular, legitimate peripheral participation (Lave and Wenger 1991), has emerged in the cognitive anthropology literature and deals with the situated nature of cognition, problem-solving, and learning, and thus seems valuable for the study of the use of IT for performing knowledge work in organizations. This theory, which helped explain differential learning among two groups of workers using desktop IT (George, Iacono and Kling 1995), is expanded and developed here, as it applies to knowledge workers, in order to guide the present research. The intent of the present research is to understand the role that the use of IT plays in knowledge workers' learning and performing their jobs.

\section{Theoretical Framework: Legitimate Peripheral Participation}

Both scholars and practitioners have discussed the nature of knowledge work. This work has been described variously as non-routine and creative (Davenport, Jarvenpaa and Beers 1996), involving human information processing (Davis 1991) or cognitive skills (Sulek and Marucheck 1994), and requiring "continuous learning" (Drucker 1995, p. 226). This type of work contrasts with more traditional forms of work where jobs are 
designed with well-defined, fixed, specific and routine tasks. Typical tasks of knowledge work are planning, decision making, problem solving and communicating, which are ill-defined and ill-structured. These tasks are generally performed using desktop information technology.

No comprehensive theories of knowledge work or the role that IT plays in performing it exist, but one situated learning theory, which may be adapted for this purpose, outlines how cognition, learning and problem solving occur in situ, rather than in the laboratory or in the classroom (Lave 1988; Lave and Wenger 1991). This theory of situated learning, legitimate peripheral participation (LPP), attempts to explain thinking and learning as a social and practical matter rather than as an individual and academic phenomenon. Given that knowledge work has a large cognitive component, involves continuous learning and occurs in an organizational setting, this theory provides a useful starting point for understanding knowledge work and the role that IT plays in performing it.

LPP has been developed from studying other types of workers and learners such as butchers, naval quartermasters and supermarket shoppers (Lave 1988; Lave and Wenger 1991; Rogoff and Lave 1984), and it includes a role for technology in general, but not for information technology specifically. Except for the study by George, Iacono and Kling, the theory has not been applied to knowledge workers. In that study, community of practice was evident in a group of knowledge workers (financial planners) and was given as the reason a group of knowledge workers used IT to serve them effectively while a group of clerical workers did not. The finer details of the theory have not been developed for knowledge workers, and the development of a role for IT in the theory has not been forthcoming.

LPP is characterized as participation in the social world and has the following main features: learning within a community of practice; learning involving the whole person and the construction of identities; a diverse field of actors including newcomers and oldtimers, where newcomers learn from old-timers and peers but where old-timers also continue to learn; and learning in practice where learning takes place in productive activities.

[LPP] provides a way to speak about the relations between newcomers and old-timers, and about activities, identities, artifacts, and communities of knowledge and practice. [LPP] concerns the process by which newcomers become part of a community of practice....[LPP] is proposed as a descriptor of engagement in social practice that entails learning as an integral constituent. [Lave and Wenger 1991, pp. 29, 35]

The choice of terms to describe this theory is revealing. "Participation" connotes the idea that learning is not the traditional notion of transfer of knowledge or skill from one person to another, or from one situation to another within the same person; rather it takes on a larger meaning of participation by the "learner" within the social world, within a community of practice. "Legitimacy" suggests the "learner's" right to participate, and the forms that that participation may take. Apprentices are generally legitimate members of their communities of practice. However, gaining legitimacy may be a problem for newcomers in some situations. For example, hazing, is one form of 
denying legitimacy; during hazing learning is inhibited. Only once they have survived hazing and gained legitimacy do newcomers occupy a place of legitimate participation, but the forms of their legitimacy of participation may vary. This latter concept is better understood when taken together with the notion of "peripherality." Peripheral participation may be contrasted with full participation, that to which peripheral participation leads. Peripherality suggests that there is no center of a community of practice and that "there are multiple, varied, more- or less-engaged and -inclusive ways of being located in the fields of participation defined by a community" (Lave and Wenger 1991, p. 36) Peripheral participation is a dynamic concept and implies that the activities of "learners" are connected and relevant to those of the community. The three terms, legitimate peripheral participation, are meant to represent a concept to be taken as a whole.

LPP includes a role for technology, but not for IT specifically:

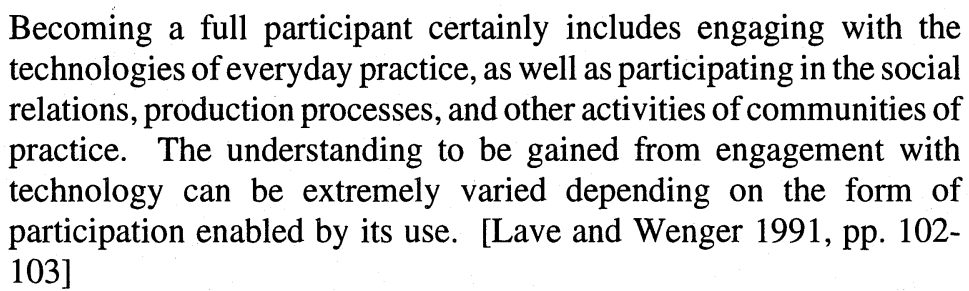

In the current research, IT is given a primary role, since it is seen as critical for performing knowledge work. Some organizations engage in such knowledge work regularly and have taken the lead in adopting various learning strategies using IT. The current, on-going research addresses three specific aspects of IT in knowledge work: (1) learning how to appropriate IT in knowledge work, (2) knowledge workers' identity with respect to using IT, and (3) the transparency of IT in knowledge work. Although LPP relates all three aspects, only the first is covered in this paper.

\section{Research Approach, Design and Methodology}

This research is based on the assumption that our knowledge of reality is socially constructed. Thus, the approach is to gain understanding of phenomena through the meanings people assign to them by studying one organization in-depth, rather than to use a survey technique across multiple organizations.

The study can be described as an in-depth, interpretive case study (Klein and Myers 1999) with embedded units of analysis (Yin 1988), but also relies on ethnographic methods such as participant observation (Agar 1996). While the design of the study is bounded by the topic under investigation (Miles and Huberman 1994), it is also a flexible design, molding to the specific organization, its design, work practices and culture (Janesick 1998).

The first author gained initial access to the firm in early October 1998. With the exception of not being able to attend client meetings or going to client sites, and the requirement to be unobtrusive, her access is relatively unrestricted, limited to her own initiative, imagination and time constraints. The primary data collection techniques to 
date have been formal interviews (since consultants travel frequently and researcher access to client sites and meetings is not permitted) and participating in a week-long, offsite training session for new consultants. Secondary techniques include observations, collection and interpretation of firm documents, use of the firm-issued laptop computer, inclusion on voice and electronic mail distribution lists, and participation in some of the firm's social activities. Consistent with ethnographic methods, the researcher also keeps a detailed set of field notes, recording how she spends her time at the site, her observations and thoughts, and issues for ongoing inquiry. To date, she has conducted 30 interviews, as follows:

\section{Position}

New analyst (less than one year with the firm)

New associate (less than one year with the firm)

Second-year analyst (between one and two years with the firm)

Associate (promoted from analyst, more than two years

with the firm)

Staff partners

Support staff

\section{Number of People Interviewed 9 \\ 5 \\ 9}

1

2

Total $\quad \frac{4}{30}$

During each interview, the researcher reminds the participant of the confidentiality of the interview and explains how anonymity will be maintained. Interviews are based on the conversational partners technique (Rubin and Rubin 1995) and are semistructured. They last 30to 90 minutes and are tape recorded and transcribed. Research participants have the opportunity to offer corrections or modifications to transcripts. This process encourages participants to speak freely during the interview.

Data collection and analysis strategies are determined by following principles proposed by Klein and Myers (1999) and Strauss and Corbin (1990). Thus data collection and analysis require giving consideration to not only the views and behaviors of individuals in the firm under study, but also to the context in which these individuals operate (fundamental principle of the hermeneutic circle, Klein and Myers 1999). Using these principles, the researcher compares findings across different respondents, documents and observations, within the context of the consulting profession and the firm under study, and uses the theory of LPP as a guide. Data collection and analysis are intertwined; analysis occurs as the data is collected and leads to further data collection and analysis. The process itself is at least partially emergent (Myers 1999). Specific analysis techniques (Miles and Huberman 1994; Strauss and Corbin 1990) include (1) writing theoretical memos, (2) drawing concept maps and (3) coding interview transcripts and documents to identify concepts, categories and their properties.

The researcher guards against bias in several ways. First, the researcher seeks multiple perspectives from participants with different backgrounds, levels of experience, and job content (principle of multiple interpretations, Klein and Myers 1999). Second, by collecting data through multiple methods-interviews, observations and firm documents, she validates many aspects of the data through triangulation (Gallivan 1997) and demonstrates "sensitivity to possible biases and systematic distortions in the 
narratives collected from the participants" (the principle of suspicion, Klein and Myers 1999). Third, the researcher engages regularly in the comparison of findings with theoretical preconceptions (dialogical reasoning, Klein and Myers 1999), and documents the comparisons with theoretical memos.

The remainder of this paper provides some preliminary data and tentative conclusions from the research. Section 6 provides the context in which this group of knowledge workers operate by describing their firm, their work and their technology environment. Section 7 provides details about the specific work of new consultants, analysts and associates, as well as the training and other mechanisms by which they prepare for this work. Section 8 discusses the research in terms of particular aspects of the theory of LPP, while the last section considers how these preliminary findings relate to theories of IT use, acceptance and training in the IS literature.

\section{Arris Strategic Management Consulting}

\subsection{Industry and Firm}

Strategic management consulting solves the strategic problems of companies, and is a profession based on intellectual capital. The major strategic management consulting firms are McKinsey, Booz Allen and Hamilton, Bain and Co. and Boston Consulting Group, whose clients are Fortune 500 and Fortune 1000 companies. Strategic management consulting is a high prestige, glamorous business where the work is intense and involves long hours and frequent travel. The pinnacle of a career in strategic management consulting is to become a partner in the firm. Many consultants, however, leave the business long before this stage to pursue other careers or interests. At Arris, in spite of the non-hierarchy, there is a strong distinction between partners and the consulting staff.

Like McKinsey and others, Arris is a global strategic management consulting firm with offices and clients throughout the world. Although Arris' origins go back several decades, the firm is relatively young, formed by mergers and acquisitions of smaller firms over the years. It is young in other ways as well: a large portion of its workforce has been with the firm for only two or three years; further, many of these people are in their twenties.

Each year Arris hires two types of entry-level consulting professionals: analysts and associates. Analysts are recent college graduates (with Bachelor of Arts or Bachelor of Science degrees) from elite institutions around the world. In the U.S., analysts are typically hired from the Ivy League institutions, as well as from other elite schools. Associates may be either recent M.B.A. graduates of top business schools or employees that have been promoted from the analyst position, either with or without an M.B.A.

\footnotetext{
I"Arris" is a pseudonym. The primary author was required to sign a confidentiality agreement with the firm, promising to disguise its identity. Therefore, some terminology and facts deemed insignificant for the analysis have been modified to disguise the identity of the firm and its members.
} 


\subsection{The Work of Arris's Strategic Management Consultants: Client Projects}

The main form of work for a strategic management consultant is a client project. The on-site researcher had the opportunity to participate in a simulated client project during a one-week training session. She was a member of an 11-member team of new hires (analysts and associates) that was headed by a junior partner. The team's mission, as put forth by the (mock) CEO of a major quick service food conglomerate, Binstar, was to propose a strategy to make Binstar's earnings grow by $10 \%$ within five years. Over the course of the next four days, her team analyzed the quick service food industry, including past and potential future trends in the industry and the competitive environment in the industry, brainstormed about possible ideas to explore further, interviewed (mock) Binstar managers and quick service food industry experts; analyzed data from a 2,000-person survey, created pro-forma financial statements for three of the most promising ideas, and prepared and presented a 50 page presentation to the CEO of Binstar (role-played by one of the Arris partners). The team leader often divided up the work for individuals or teams of two or three consultants to work in parallel on different aspects of an analysis. The team was provided with information packs progressively throughout the week which contained, for example, industry reports, Wall Street analysts' reports, Binstar's and other firm's annual reports, and a SAS cross-tabulation report for a 2,000-subject, 50-variable survey. Each consultant had been instructed to bring his laptop computer to the training (see section 6.3). A large portion of the work done during the week, especially economic and market analyses and presentation of ideas and results, was facilitated by consultants' use of their laptop computers. The researcher was not equipped with a laptop computer and as a result felt handicapped in participating in the work (Field Notes: 1-8-99).

The Binstar project represents the type and intensity of work in strategic management consulting. Client projects take a variety of forms and are typically staffed with a team of consultants with varying experience. The average length of a project is three to four months and deadlines with "deliverables" constantly loom over the team. Unlike the Binstar simulated project, where the team was composed of new hires, a typical project team includes a partner, a junior partner or senior associate, two or three associates and two or three analysts. In most cases, the roles of the different team members are as follows. The partner sells the project to the client and maintains the relationship with the client to set and maintain expectations. The junior partner or senior associate on the project acts as the team and project manager, assuring that work promised to the client meets expectations and is completed on time. This team manager also acts as a buffer between the partner and the consulting staff (i.e., associates and analysts) (Interview Transcript). Associates and analysts conduct research, perform market and economic analyses, and prepare written presentations.

To support this work, the New York office has a research library staffed with two full-time librarians, a production department to assist in producing client presentations, and an information systems department staffed with two full-time information systems technicians who service computers, printers and the local network. New York-based consultants are not limited to the support of New York-based resources. In particular, a marketing sciences group operates out of another office and assists with projects which require complex statistical or other analyses. Further, one consultant described how she 
uses the time difference of geographically dispersed offices to keep production (in the different offices) working around the clock on a time-critical document (Interview Transcript).

\subsection{Information Technology Environment at Arris}

Although several consultants have indicated that Arris is behind its competitors in terms of the information technology environment, some have been quick to point out that the environment has improved over the years. Each consultant is provided with a firmissued laptop computer, which has been pre-configured by the IS department. A typical configuration includes Windows 95 operating system, Microsoft Office 97 (Excel, Powerpoint, Word, Access), Novell network access to Arris local and remote servers and printers, Microsoft Outlook 98 (e-mail), Microsoft Explorer for access to the Internet and to Arris intranet and knowledge management system, and pre-configured spreadsheets for tracking time and expenses. Powerpoint has been customized with the addition of over 100 custom templates, which are available via a special pull-down menu from within the Powerpoint application. Consultants sometimes use more powerful computers and specialized software such as SAS, SPSS or Knowledge Seeker.

Using IT is a natural part of consultants' work (but not necessarily of the partners' work), so much so that some consultants take it for granted. At the Binstar training, one of the new associates, knowing the general area of this study, commented "It's unfortunate for you that we didn't really use any IT during the project simulation." When the researcher referred to the laptop computers, the associate said, "Oh, I didn't think of that because we use it all the time" (Field Notes 1-8-99). Others realize that using IT is a necessary condition of their working lives. One of the new analysts expressed this view:

I think that the more that information technology gets ingrained in what we do, when someone comes in without a capability, [he's] behind to a degree, so [he's] forced to learn it quicker just because everyone around him is using those programs. So, if five years ago we weren't using computers, that means now, if your interest wasn't in computers or IT, you have to learn that because that's a skill you have to have....[M] ost of the work we do in some way involves information technology, either the analyses or manipulating data. That goes on in Excel or sometimes statistical packages. [Interview transcript]

Arris is a firm where IT is integrated into consultants' lives. (For partners, it may be a different story, which we shall tell in future research!)

Using IT is a complex activity for consultants. They regularly work with a variety of information technology, including spreadsheets, databases, statistical software, presentation software, electronic mail, file transfer and download functions, and electronic searching software. Further, they interact with the information technology by building models, manipulating data, preparing charts, etc. Their interaction goes beyond data input and reading output to include, for example, searching for functions and 
writing them into formulas in Excel and statistical packages, writing and testing queries in Access, and manipulating fonts, objects, text and diagrams in Powerpoint. These knowledge workers clearly belong in the upper right quadrant of Figure 1.

\section{First Job as a Strategic Management Consultant}

\subsection{New Analysts and Associates: Recruiting, Hiring, the Job}

Recruiting is serious business since Arris runs on intellectual capital. As one partner expressed it: "It's a people-oriented business....We do not make products. We sell the intellectual capital of the firm" (Interview Transcript) For candidates, it is serious because a job at Arris provides lots of opportunity, not just while at Arris, but post-Arris, as well. One new analyst expressed his reasoning like this:

I'm not really sure what I want to do with my life so this is probably something that will definitely be good for a little while, maybe for a long while, and won't hurt my chances in anything else if I decide there's something else I want to do. [Interview Transcript]

Strategic management consulting is a high burn-out business, and high turnover is expected. A partner explained it this way: "Consulting years are like dog years....You spend one in consulting; it's like seven in any other business" (Interview Transcript). Thus, each year Arris hires a new crop of young, fresh-faced, highly intelligent, welleducated, energetic, and sociable analysts and associates. Firm-wide, Arris hired approximately 150 new consultants in 1998 .

Getting a job as a strategic management consultant is an achievement and a performance. The recruiting season for new analysts starts in the Fall, when potential candidates check out Arris' Web site, or more likely talk to a friend who is already at Arris. Candidates submit resumes (hoping to get past the initial screening), pass oncampus interviews, and eventually get invited to New York for more interviews and socializing. Those who succeed get an offer, and then get wined and dined in Manhattan at Arris' expense.

The task is no less demanding for current members at Arris, who must allocate time in their busy schedules to interview and socialize with candidates and convince them to join Arris rather than a competitor. The task is especially daunting with regard to hiring new associates (Reingold 1998). Within Arris, lists of candidates are maintained formally, along with the probability of their joining the firm. A team of people is assigned to monitor the candidate's inclinations toward Arris, answer any questions and concerns the candidate may have during the courting process, and generally to convince the candidate that Arris is a great choice.

For analysts, their experience at Arris is generally their first full-time, long-range (i.e., at least two years) job experience. Analysts are junior members of any client project; their work generally involves performing discrete modules or tasks under the supervision of a more experienced consultant or partner. "Analysts are professional members of [Arris] and take on a variety of responsibilities from carrying out data collection and essential research to conducting complex quantitative, financial and 
strategic analyses of businesses and corporations" (1998 Arris recruiting brochure). Analysts have several career paths, including staying with Arris through promotions, leaving Arris after two years to attend business school (and then returning, or not, to Arris as an associate), or leaving Arris to do something else. Analysts have varied educational backgrounds, in liberal arts, engineering, business, etc.

New associates are recent graduates of top M.B.A. programs and "in the early stages of their careers Associates are responsible for research and analysis as well as packaging findings" (1998 Arris recruiting brochure). Associates typically have prior work experience, usually in another field, but sometimes as former analysts at Arris who have accepted Arris' offer to pay for their graduate degrees and hire them upon graduation from the M.B.A. program.

New consultants are drawn to the work for several reasons. Many expressed the desire to be in an environment where they would learn continuously through their work, where they would be exposed to a variety of industries and client problems, where they would be surrounded by other bright people, and where they would learn valuable skills. They expect to be challenged to learn new industries and skills and are motivated by the prospect. Coming from top educational institutions, they expect to pick up many skills on their own, with minimal formal training. A couple of analysts expressed an alternative to this basic motivation. One indicated that the reason they were all there was for the salary that would allow them to pay off student loans and at the same time live a certain lifestyle in Manhattan. But many pointed out that they had chosen management consulting over investment banking (where salaries are generally higher) for a broader exposure to industries and skills, as well as to avoid the 100-hour work weeks (consultants only work 60,70 or 80 hours!). Another indicated that while learning on the job was not an unusual demand, learning a new task and a new software tool late at night when you're exhausted, with a looming deadline, was perhaps expecting too much.

I definitely learned, but it wasn't the best way to learn this. There was a lot of work, a lot of pressure, and I felt really poorly equipped to deal with it. Go run a query and make a pivot table is not a big deal. But when you're figuring out the finance, and trying how to figure it out in Excel, and then you're getting error messages because the data isn't flawless, it's a little bit much to handle, you know, at midnight, when you're getting really, really tired, and you're wondering why you took this job to begin with. [Interview Transcript]

\subsection{Formal Training}

All new analysts and associates (even those former analysts returning to the firm as associates) attend the same training sessions. New analysts and associates attend two mandatory training sessions. The first is a two-week session held in September when the majority of new hires begin their jobs. Each new consultant receives two thick binders covering the topics in training plus additional support materials. The September training covers "Orientation" training and "Tools of the Trade" training. Orientation introduces consultants to Arris and covers topics such as the Arris' growth and organization, employee benefits, travel and entertainment policies, staffing and mentoring, upward and 
downward employee review procedures, tips for traveling, and other administrative and practical advice. "Tools of the Trade" training covers functional areas, such as basic finance and accounting, and specific skills training, such as building spreadsheet models with Excel, conducting regression analysis, and when to use Access database software.

The second mandatory training session for new consultants, called "Project Simulation," occurs in January. This training occurs off-site, where new consultants from around the world meet at a five-star hotel to attend lectures, "solve" a simulated client project as part of a project team, and socialize together (see section 6.2).

\subsection{Other Training, Other Mechanisms, Other People}

In addition to the two formal training sessions provided for new consultants, other types of optional training are available. These include computer-based training (CBT), informal workshops offered periodically in the office, and informal workshop documents and tutorials available for down-loading from the server.

Beyond training and self-taught tutorials, consultants turn to others when they encounter something new or have a problem doing an analysis. While a few consultants are content to learn from books, manuals, or tutorials, the majority prefer to employ a strategy of asking others when the need-to-learn situation arises.

\section{Discussion}

\subsection{Community of Practice at Arris}

According to LPP, legitimacy occurs through productive work activities, and learning is dependent on newcomers' having legitimacy in the community and having access to members and resources of the community, rather than on formal training. At Arris, new consultants are engaged in productive work activities, i.e., assigned to a client team, very soon after joining the firm, with very little formal training. Further, they have wide access to other consultants and to resources such as information technology, and they are encouraged to seek out others and ask questions. Through engagement in productive work activities, consultants are expected to learn their work and how to use IT.

LPP suggests that newcomers will initially occupy less-engaged locations in the community. At Arris, this form of participation is manifest in new consultants' being assigned discrete tasks and being guided or directed in which IT to use to perform the task and how the IT may be used to perform the task. One experienced consultant explained a newcomer's role in these terms: "It's hard to strike a balance between telling someone exactly what you want and telling them basically where the case is going and allowing that person to think about it and come back with his first cut at it" (Interview Transcript). 


\subsection{The Role of Formal Training}

The majority of new consultants interviewed stressed the importance of "learning-onthe-job" and learning from other people. While they recognized the importance of having a foundation, acquired either through their prior education or through training, they felt that the only way to really understand their jobs and tasks was by actually doing them. With respect to learning the software tools, one consultant explained,

You just have to do it. You can read about it, but it's different. You have to just do it. It's helpful to read about it and have that as reference material, but you're the one who's going to have to do it at three in the morning. You should figure it out. [Interview Transcript]

Another recounted,

I'm a firm believer that you can go through training, and you can sit at your computer and get familiar with how to use the package, but I think the learning is more experiential as opposed to something that can be taught. It's more learning-by-doing as opposed to memorizing or getting familiar with what you're supposed to be doing. [Interview transcript]

Most implementation initiatives of information systems include training users in how to use the system as an important element of the implementation. Training is often conceived of as occurring in a formal classroom setting, shortly before or after the system goes live. Some people have suggested continuous training for effective technology use (Strassmann 1990). Some recent research points to the ineffectiveness of traditional, formal training for knowledge workers and to the importance of peer networks for learning to use IT for effective work performance (George, Iacono and Kling 1995). Thus, although conventional wisdom advocates formal training programs for learning about performing jobs and how to use IT, this research demonstrates that formal training plays a limited, although important role, especially with respect to using IT for consulting work.

\subsection{Using IT to Learn the Job and Using the Job to Learn IT}

These knowledge workers recognize that they are continual learners. Many took the job for that reason. What they may not recognize is that at the same time they are learning how to use the information technology, the information technology is helping them to learn their jobs. There is a duality in learning. Most are confident that they will learn to use the technology when they need to. In this respect, they are using their jobs to learn about IT. While performing an economic analysis, an analyst will sharpen his skills in Excel, through practice, discovery, errors, frustration and asking others. At the same time, by using Excel, he may sharpen his problem-solving and problem-structuring 
skills, learning how to lay out the spreadsheet. One associate indicated how using the software helps to understand analytical tasks,

I think that, or would hope that, the software program like Excel helps Analysts understand the analyses they are doing....For instance, you can plug numbers into a formula, and have it spit something out at you, but in order for that number to make sense, you have to think about how that formula is structured, and the inputs you put in. [Interview Transcript]

IT helps consultants learn their jobs in the conventional ways as well, through computerbased training, and by providing access to information.

This duality in learning could account for the tremendous difficulties experienced by some consultants who have limited backgrounds in using IT. They stumble over the IT in using it, do not understand why one program is more appropriate than another and cannot plan work, which will use IT and which is to be done by others. As a result they are less effective in performing their jobs. Happily, the majority of consultants come to the organization with a fair amount of experience using information technology. Some do not recognize this, but when pressed, they recalled programming courses they had taken in high school, software packages they had used in college and computer camp they had attended as children.

\section{Conclusion}

This paper presents early findings of an on-going interpretive case study of knowledge workers at a strategic management consulting firm. One of the benefits of ethnographicstyle research is that it challenges the assumptions we hold (Myers 1999). The initial findings of the present research challenge several assumptions implicit in the IS literature, thereby suggesting avenues for future lines of inquiry. Theories of technology acceptance, such as TAM (Davis, Bagozzi and Warshaw 1989) and Task-Technology Fit (Goodhue 1995), and models of training (Bostrom, Olfman and Sein 1990) typically take an individualistic approach, giving little, if any, weight to group effects, yet the present research indicates that the community of practice has an important influence on these knowledge workers. These same theories typically consider a single information system or software program, yet the knowledge workers at Arris use a multitude of information systems and software programs. While the IT literature on training emphasizes formal, structured training, formal training is just one mechanism by which these knowledge workers learn their work and how to appropriate information technology. The knowledge workers of this study learn their jobs and how to appropriate IT from their peers, superiors and subordinates.

Future lines of inquiry could explore details of the community of practice. For example, what is the composition of the different communities of practice? Are there different communities of practice for learning different aspects of the job and information technology? Given that knowledge workers use a multitude of information technologies, one might ask, what are the implications for transfer of skills across information 
technologies? Future lines of inquiry could also address training issues, such as how can formal IT training be made effective? What structure should on-going training take?

The obvious limitation of this study is that it investigates a single firm and group of knowledge workers. Conclusions drawn here regarding the importance of informal, onthe-job learning may not generalize to other groups of knowledge workers at other management consulting firms or to different industries. For example, the quick minds of Arris consultants, their curiosity, and desire for challenge may account for their propensity to learn on-the-job rather than through formal training. Similarly, their highly outgoing personalities may explain their preference for learning from others around them.

In spite of the study's limitation, it offers valuable insight into the incorporation of information technology into the working lives of knowledge workers at one organization. Based on these early findings of this study, extant theories of technology use and acceptance could be modified to incorporate the complex dimensions of knowledge workers' jobs as discussed here, and as represented in Figure 1. For example, theories explaining individual user adoption of technology and user training may be broadened to account for the community of practice and the multitude of systems and functionality knowledge workers have at their disposal. Training research may be extended to include the effects of the community of practice and to consider the structure of an on-going professional development and information technology training program. Finally, in terms of reward systems, firms may need to modify their incentive policies to recognize and encourage the mentoring and information-sharing across the community of practice. Just as the adoption of groupware and knowledge management systems have incited firms to alter traditional reward structures to acknowledge individual knowledge-sharing (Davenport, Jarvenpaa and Beers 1996; Orlikowski 1996), so may firms need to encourage individual mentoring, sharing, and information-seeking behaviors in the work environment.

\section{References}

Agar, M. The Professional Stranger. San Diego, CA: Academic Press, Inc., 1996.

Barley, S. "The Alignment of Technology and Structure through Roles and Networks," Administrative Science Quarterly (35), 1990, pp. 61-103.

Bell, D. The Coming of Post-Industrial Society. New York: Basic Books, Inc., Publishers., 1973.

Bostrom, R. P.; Olfman, L.; and Sein, M. K. "The Importance of Learning Style in End-User Training," MIS Quarterly, March 1990, pp. 101-119.

Brown, J. S., and Duguid, P. "Organizational Learning and Communities-of-Practice: Toward a Unified View of Working, Learning, and Innovation," Organization Science (2:1), 1991, pp. 40-57.

Davenport, T. H.; Jarvenpaa, S. L.; and Beers, C. “Improving Knowledge Work Processes,” Sloan Management Review, (Summer 1996, pp. 53-65.

Davis, F. D.; Bagozzi, R. P.; and Warshaw, P. R. "User Acceptance of Computer Technology: A Comparison of Two Theoretical Models," Management Science, (35:8), 1989, pp. 98210003.

Davis, G. "Conceptual Model for Research on Knowledge Work," MISRC Working Paper, University of Minnesota., 1991.

DeLone, W. H., and McLean, E. R. "Information Systems Success: The Quest for the Dependent Variable," Information Systems Research (3:1), 1992, pp. 60-95. 
DeLong, D. W. "My Job is in the Box": A Field Study of Tasks, Roles, and the Structuring of Data Base-Centered Work, Unpublished Dissertation, Boston University, Graduate School of Management, 1997.

Devin, P. "Porsche People and Ford Folks: Different Patterns of Using User-Modifiable Interfaces," Working Paper, Department of Information Systems. New York, New York University, 1994.

Drucker, P. F. Post-Capitalist Society. New York: Harper Collins Publishers, 1993.

Drucker, P. F. Managing in a Time of Great Change. New York: Truman Talley Books, 1995.

Fisher, K., and Fisher, M. D. The Distributed Mind: Achieving High Performance through the Collective Intelligence of Knowledge Work Teams. New York: Amacom, American Management Association, 1998.

Gallivan, M. J. "Value in Triangulation: An Analysis of Two Approaches for Combining Qualitative and Quantitative Methods," in Qualitative Research in Information Systems, A. S. Lee, J. Liebenau and J. DeGross (eds.). London: Chapman \& Hall, 1997, pp. 417-444.

George, J. F.; Iacono, S.; and Kling, R. "Learning in Context: Extensively Computerized Work Groups as Communities-of-Practice," Accounting, Management and Information Technology (5:3/4), 1995, pp. 185-202.

Goodhue, D. "Understanding User Evaluations of Information Systems," Management Science (41:2), 1995, pp. 1827-1844.

Janesick, V. J. "The Dance of Qualitative Research Design: Metaphors, Methodolatry, and Meaning," Strategies of Qualitative Inquiry, N. K. Denzin and Y. S. Lincoln (eds.). Thousand Oaks, CA: Sage Publishing, 1998, pp. 35-55.

Klein, H. K., and Myers, M. D. "A Set of Principles for Conducting and Evaluating Interpretive Field Studies in Information Systems," MIS Quarterly, Special Issue on Intensive Research in Information Systems Using Qualitative, Interpretive, and Case Methods to Study Information Technology (23:1), 1999 forthcoming.

Kling, R., and Scacchi, W. "The Web of Computing: Computer Technology as Social Organization," Advances in Computers (21:1), 1982, pp. 1-90.

Laudon, K. C., and Starbuck, W. H. "Knowledge and Information Work in Organizations," Working Paper, Stern School of Business, New York University, 1994.

Lave, J. Cognition in Practice. Cambridge, England: Cambridge University Press, 1988.

Lave, J., and Wenger, E. Situated Learning: Legitimate Peripheral Participation. Cambridge, England: Cambridge University Press, 1991.

Lucas, H. C., Jr. The T-Form Organization. San Francisco: Jossey-Bass Publishers, 1996.

Mankin, D.; Cohen, S. G.; and Bikson, T. K. Teams and Technology: Fulfilling the Promise of the New Organization. Boston: Harvard Business School Press, 1996.

Miles, M. B., and Huberman, A. M. Qualitative Data Analysis. Thousand Oaks, CA: Sage Publications, 1994.

Myers, M. "Ethnographic Research Methods in Information Systems," IS World Net Virtual Meeting Center at Temple University, March 8-11, 1999 (online). Available at http://interact. cis.temple.edu/ vmc(click on "guest").

Orlikowski, W. J. "The Duality of Technology: Rethinking the Concept of Technology in Organizations," Organization Science (3:3), 1992, pp. 398-427.

Orlikowski, W. J. "Improvising Organizational Transformation Over Time: A Situated Change Perspective," Information Systems Research (7:1), 1996, pp. 63-92.

Reingold, J. “And Now, Extreme Recruiting,” Business Week, October 19, 1998, pp. 97-100.

Rogoff, B., and Lave, J. (eds.). Everyday Cognition: Its Development and Social Context. Cambridge, MA: Harvard University Press, 1984.

Rubin, H. J., and Rubin, I. S. Qualitative Interviewing: The Art of Hearing Data. Thousand Oaks, CA: Sage Publications, Inc., 1995. 
Ruhleder, K.; Jordan, B.; and Elmes, M. B. "Wiring the 'New Organization': Integrating Collaborative Technologies and Team-Based Work," Annual Meeting of the Academy of Management, 1996.

Schultze, U. "A Confessional Account of an Ethnography About Knowledge Work," MIS Quarterly, Special Issue on Intensive Research in Information Systems Using Qualitative, Interpretive, and Case Methods to Study Information Technology, 1999.

Strassmann, P. A. The Business Value of Computers. New Canaan, CT: The Information Economics Press, 1990.

Strauss, A., and Corbin, J. Basics of Qualitative Research. Newbury Park, CA: Sage Publications, Inc., 1990.

Sulek, J., and Marucheck, A. "The Impact of Information Technology on Knowledge WorkersDeskilling or Intellectual Specialization?” Work Study (43:1), 1994, pp. 5-13.

Turner, J. A. "Computer Mediated Work: The Interplay Between Technology and Structured Jobs," Communications of the ACM (27:12), 1984, pp. 1210-1217.

Tyre, M. J., and Orlikowski, W. J. "Windows of Opportunity: Temporal Patterns of Technological Adaptation in Organizations," Organization Science (5:1), 1994, pp. 98-118.

Yin, R. K. Case Study Research Design and Methods. Thousand Oaks, CA: Sage Publications, 1988.

Zand, D. E. The Leadership Triad. New York: Oxford University Press, 1997.

\section{About the Authors}

Valerie Spitler is a candidate for the Ph.D. degree in the Information Systems Department at New York University's Stern School of Business. Valerie's research focuses on knowledge work and the role that information technology plays therein. After attending the 1997 IFIP WG8.2 conference on qualitative research in information systems, she decided to conduct qualitative research for her dissertation. She holds an M.B.A. from INSEAD (France) and a B.S. from the Wharton School.

Michael Gallivan is an Assistant Professor in the Computer Information Systems Department at the Robinson College of Business at Georgia State University in Atlanta. He holds a Ph.D. from the Sloan School of Management at MIT, and was an Visiting Assistant Professor at the Stern School of Business, New York University, prior to arriving at Georgia State University.. Mike's research focuses on the individual and organizational factors that influence implementation of technology innovations among both IT professionals as well as end users. In particular, he is interested in individual and group-level learning that occurs within organizations. Mike is currently investigating how organizations can develop sustainable competitive advantage through judicious use of outsourcing IT, and developing effective partnerships to manage such relationships. In addition to examining more IT outsourcing strategies, he is also examining interorganizational exchange relationships specifically analyzing the role of trust in virtual relationships across firm boundaries. He can be reached by e-mail at MGallivan@gsu.edu. 